\title{
CORRIGENDUM
}

\section{Multiple origins of linear dunes on Earth and Titan}

David M. Rubin and Patrick A. Hesp

Nature Geoscience 2, 653-658 (2009); published online: 16 August 2009; corrected after print: 24 January 2010.

In the version of this Article originally published, one of the data points in Fig. 3 was incorrect and should have been as shown here. This error has been corrected in the HTML and PDF versions of the Article.

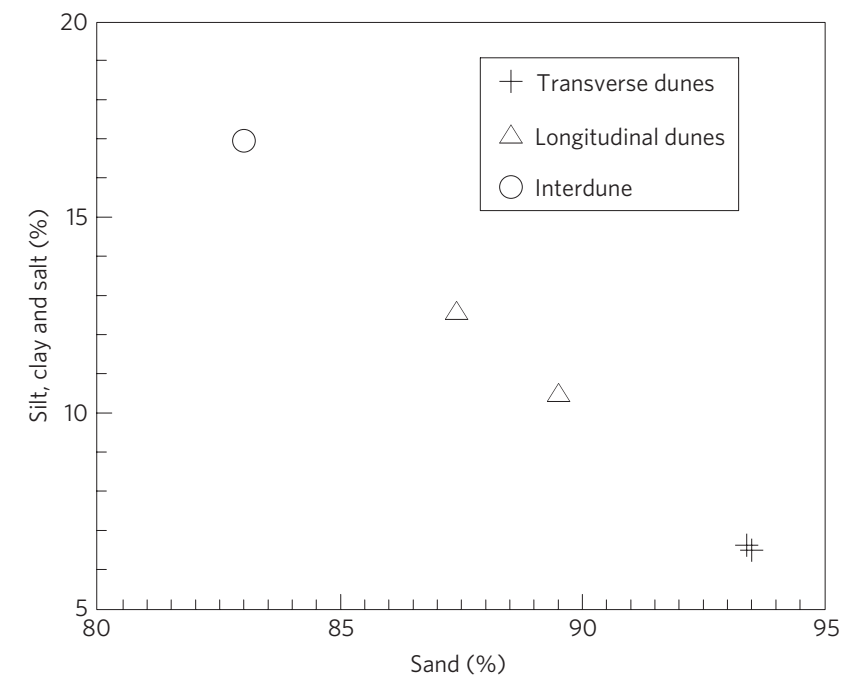

